\title{
Tablet Y289 the Babylonian Physics Tablet
}

\section{Paul TE Cusack*}

1641 Sandy Point Rd, Saint John, Nb, E2k 5e8, Canada

Submission: January 11, 2018; Published: May 25, 2018

*Corresponding author: Paul TE Cusack, 1641 Sandy Point Rd, Saint John, Nb, E2k 5e8, Canada, Email: st-michael@hotmail.com

Keywords: Babylonian; Circumference; Ancient; Infinite; Universe; Speed; Area; Decimals; Permeability; Termination; Universal Density; Eigenvector; Tablet; Physics

\section{Opinion}

My interest in Mathematical Physics began with the problem of the termination of two infinite numbers, $\pi$ and e. The solution is where the circumference of a circle equals the Area subtended by the circle. The both rely on $\pi$. Since the universe is a physical reality, $\pi$ cannot logically be infinite. It terminates, as the Babylonians knew, at 6 and 1/6. This is shown below [1]. The conclusion is that the Babylonians knew more Physics than we knew today, henceforth. This Tablet's interpreted shows how much Mathematical Physics the Ancients knew. It is amazing that they knew so much. I don't think we had any idea (Figure 1). The Area of a circle is the derivate of the circumference of it. The rate of change of Area is equal to the circumference at R- $=2$. If we set circumference $=2.9989$, the speed of light according to the Babylonians,

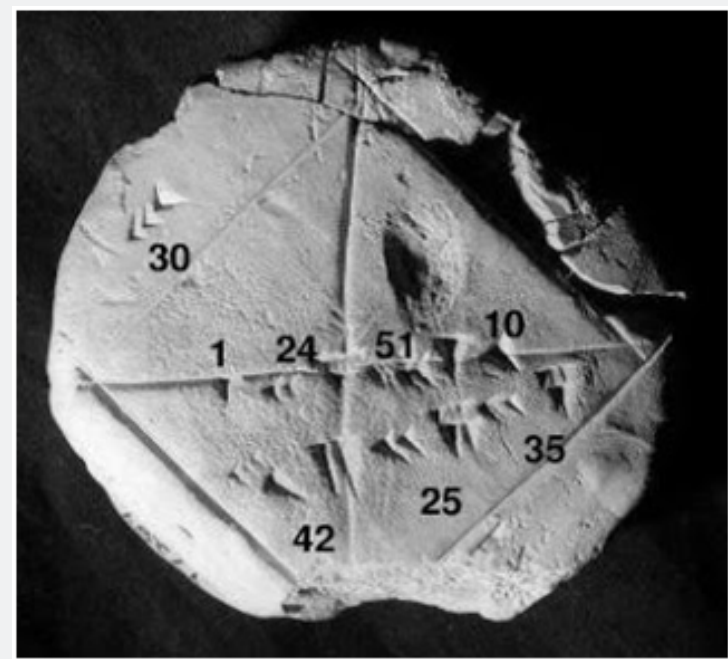

Figure 1: YBC289.
Circ $=2 \pi R=2 \pi R=2.9989 R=1.4995 * \pi=4.71=2+e=d M / d t+e=$ $=1 / 2123$ Or Feb 12 at $3 \mathrm{AM}$.

Since the universe is a physical reality, and it is dependent upon $\pi, \pi$ must terminate at where the circumference equals the area of a circle. The Area and the circumference are both dependent upon $\pi .6$ decimals are where $\pi$ terminates. Engineers never need more than 6 significant digits [2].

I can read this tablet from Samaria YBC 289. It is a Babylonian Tablet that records all the Physics they knew.

$30=03=c=$ speed of light

$0115=115=1.15=$ sqrt $3 * 2 / 3=1.15=1 / \sin 60$ degrees, $1 / \mathrm{F}$

$1 / 51=196=\infty$

\section{$51 / 4.482=11381 / 1138$}

Permeability $885 / 51=1.73=\sqrt{3}=$ Eigenvector $=\mathrm{t}$

$0.885 / 4.482=01 / 51$

$42=\operatorname{cuz}=\pi-e$

$25 \& 35$ are read backwards giving 5352. $\sin ^{\wedge}$ $1(0.5252)=32.35$ degrees . This is $1 / \sqrt{\mathrm{Pi}}$

32 in the cubed root tables of Samaria $=3.1744 \sim \pi$

freq $\left.^{\wedge} 0.333=31.8\right)^{\wedge} 0.333=3,16 \sim \pi$ and $\sin ^{\wedge}-1(0.5325)=32.27$ degrees $=0.5616 \mathrm{rads}$

$0.5616=1 / 0.1781 * 2 \mathrm{Pi}=0.1119=\mathrm{c}^{\wedge} 2$

c=2.9893 speed of light.

$1 \& 24$ are read $421-2.718=1 / 254=1 /$ Period T 
$421-271=0.666=\mathrm{G}$ and therefore the Mass Gap

$4.486 / 0.42 / \sqrt{2}=0.868=\sin 60$ degrees

$4.486 / \mathrm{cuz} / \sqrt{2}=0.1336=\mathrm{s}$

$\mathrm{S}=|\mathrm{E}||\mathrm{t}| \sin 60$ degrees $\theta=60$ degrees

$4.486 / 0.4233 /$ sqrt $3=16=\mathrm{R}$
E,t,s,c G, M, T, freq, cuz, $\pi, e, M, F, t, R$, theta, Eigenvector, Eigenvalue $=c$

This is what the Babylonians knew in $2000 \mathrm{BcE}$, or before [3]. They knew all this Physics, which henceforth was not known till this day. So how did the Babylonians know all this? They knew a lot more than just the sqrt 2 as suggested by Figure 2

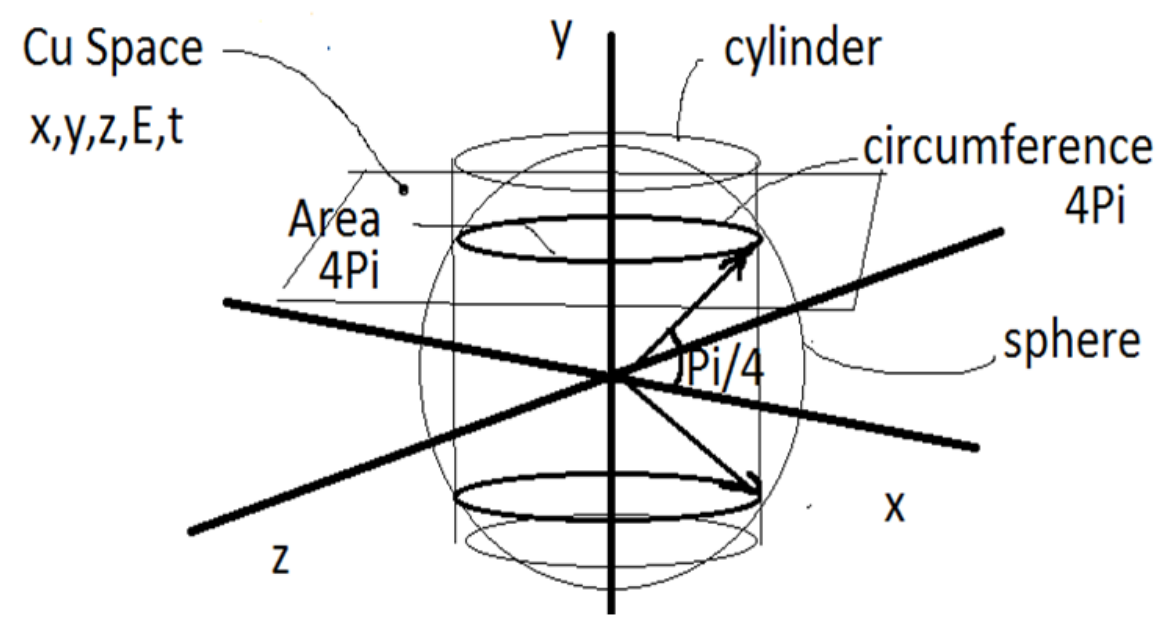

Figure 2: CU-SPACE rotated 45 degrees, in profile, is the square with the double diagonals. They would be the vectors here. The area of the cones is $2^{*} \pi / 2=\pi$. Measuring the tablet will indicate the degree of accuracy of the Babylonian $\pi$. I think it may be to 6 decimals.

Note the following:

$\pi=3.14159=$ God

$3 * 1 / 3 * 1 * 4 * 1 / 4 * 1 * 5 * 1 * 9 / 5$ Pi to six decimals 3.14159 .

$=3$

$\pi / 3=60$ degrees $=$ Sexigesimal System

$2 \mathrm{Pi} / 3=0.666 \mathrm{Pi}$

Pi evil, evil evil god

$2 * 7 / 2 * 7 * 1 / 7 * 1 * 1 / 1 * 8 * 1 / 8 * 8 / 2 * 2 * 8$

$7 / 2 * 1 * 8 * 2 / 8 * 8 / 2$

$=4488$

$=$ Mass $\mathrm{M}=4.486$

$4.171=(2+\mathrm{e})$

$\operatorname{Ln}(2.388) / \operatorname{Ln} \mathrm{e}=3.173 / 1=\sqrt[3]{32 \sim \pi}$

$\mathrm{e} / \pi=0.8653=\sin 60$ degrees

$3 * 1 * 4 * * 1 * 5 * 9=54$

$54 / 9=6$ decimals.

Evil $=6=54 / 9$
$5=$, Holy Spirit, $4=$ me, $9=$ Holy Spirit

$(5 * 4) / 9=20 / 9=0.222=1 / 45$

$1 /(4+5)=1 / 9==0.111=1 / c^{\wedge} 2$

I think this is a method to terminate an infinite number. It is where the circumference $=$ Area of a circle.

$A^{\prime}=\operatorname{circ}=\pi R^{\wedge} 2=2 \pi R$

$\mathrm{R}=2$

$A^{\prime}=C=4 \pi$

Circ $=2 \mathrm{PiR}=3$ (Termination of $\pi)$

$\mathrm{R}=4775$

$\mathrm{R}$ (in reverse) $=5774=1 / \sqrt{3}=5774=\tan 60$ degrees

3761 BCE -1 (No year zero) $+5774=2012$

Christian Calendar is off by 4 years. (Christ born in $4 \mathrm{BcE}$, December 25)

$2012+4=2016$ AD.

$A^{\prime}=\pi\left(6^{\wedge} 2\right)=36 \mathrm{Pi}=11.3097=1 / 0.884=$ Permeability

$113.097 / 511=0.2213$

Sin $0.2213=0.1278=\rho=$ Universal Density 
Hanging Gardens of Babylon (Nineveh)

On another matter, the Ancient Hanging gardens of Babylon, were likely built in Nineveh, because Jonah was to preach there. Jesus said that "There is something more than Jonah here." The Gardens would have been 81 feet high, since $1 / 81=0.12345679$ related to the Mass of the universe. Or $24 \mathrm{~m}=7.87$ feet $1 / 787$ $=0.127=\rho$. There would have been 7 levels $0-7$. The other physical constants listed above would have been built into the structure symbolically. Here are possible calculations Babylonian Engineers would have made (Figure $3 \& 4$ ).

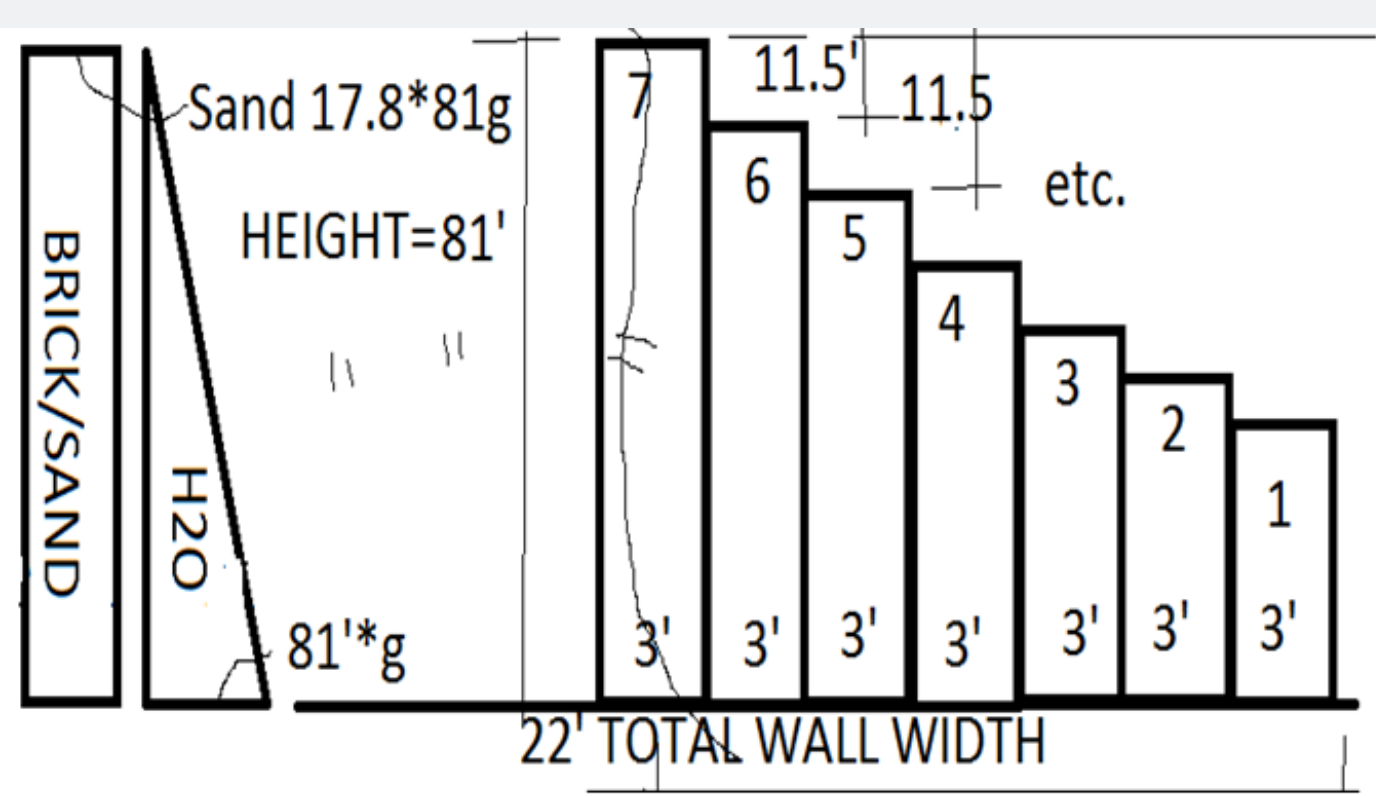

Figure 3: Brick and Sand Load on Garden Foundation.

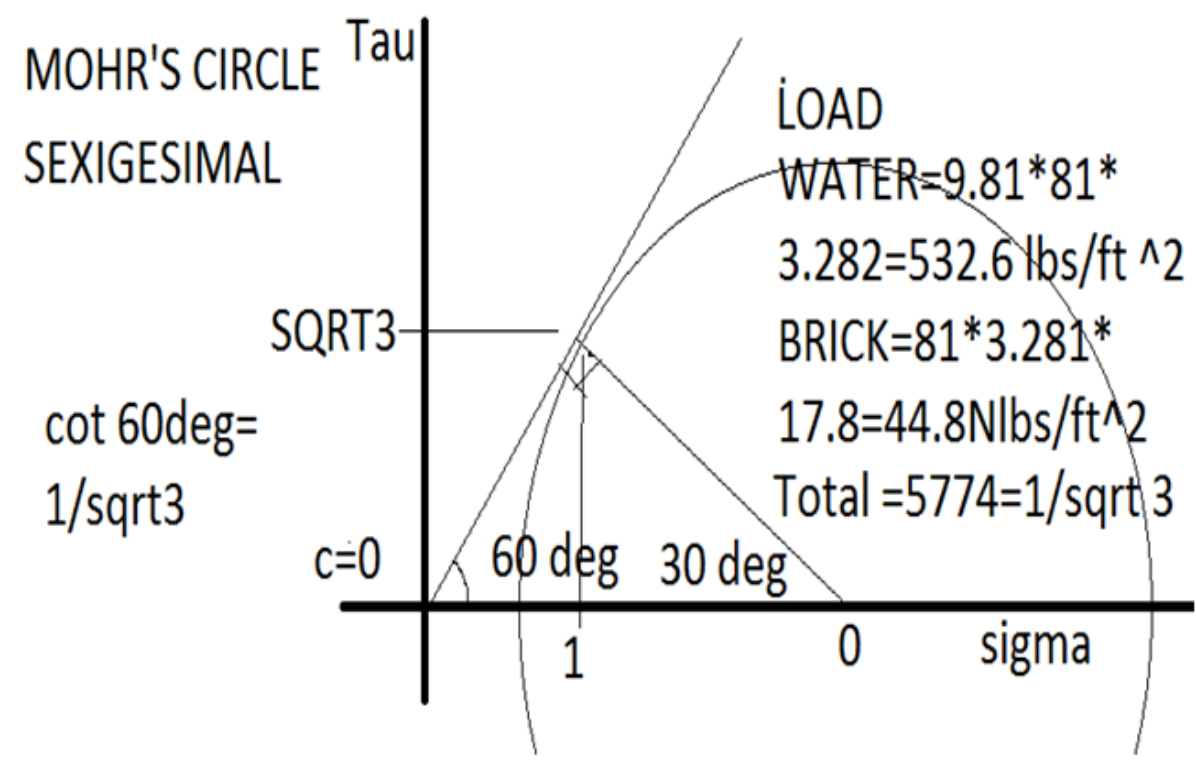

Figure 4: Soil Mechanics calculations using Mohr's Circle for Shear and Vertical Stresses.

\section{References}

1. History Beta (2018) Which Babylonian tablets contains the list of squares and cubes?

2. Ron Cowen(2016) Math whizzes of ancient Babylon figured out forerunner of calculus.

3. Blogger http://www.britannica.com/story/ancient-babyloniansused-advanced-geometry Astrotheology CUSACK'S UNIVERSE 4300 PLUS POSTS. 


\section{Your next submission with Juniper Publishers} will reach you the below assets

- Quality Editorial service

- Swift Peer Review

- Reprints availability

- E-prints Service

- Manuscript Podcast for convenient understanding

- Global attainment for your research

- Manuscript accessibility in different formats

( Pdf, E-pub, Full Text, Audio)

- Unceasing customer service

Track the below URL for one-step submission https://juniperpublishers.com/online-submission.php 